\title{
Time Weighted Portfolio Optimisation
}

\author{
A Paper Presented at the $8^{\text {th }}$ Annual \\ European Real Estate Society Meeting \\ Alicante Spain \\ June, 2001
}

\author{
Stephen Lee* \& Simon Stevenson* \\ * Department of Land Management and Development, \\ Faculty of Urban and Regional Studies, \\ The University of Reading, Reading RG6 6AW, England.
}

Phone: +44 118931 6338, Fax: +44 118931 8172, E-mail: S.L.Lee@ @reading.ac.uk

\$ Department of Banking \& Finance,

Graduate School of Business,

University College Dublin, Blackrock, County Dublin, Ireland.

Phone: +353 1706 8825, Fax: +3531283 5482, E-mail: simon.stevenson@ucd.ie http://www.ucd.ie/gsb/Banking_Finance/staffss.htm

\begin{abstract}
In estimating the inputs into the Modern Portfolio Theory (MPT) portfolio optimisation problem, it is usual to use equal weighted historic data. Equal weighting of the data, however, does not take account of the current state of the market. Consequently this approach is unlikely to perform well in any subsequent period as the data is still reflecting market conditions that are no longer valid. The need for some return-weighting scheme that gives greater weight to the most recent data would seem desirable. Therefore, this study uses returns data which are weighted to give greater weight to the most recent observations to see if such a weighting scheme can offer improved ex-ante performance over that based on un-weighted data.
\end{abstract}

Key words: Time-weighted returns and Ex-ante Portfolio performance 


\section{Time Weighted Portfolio Optimisation}

\section{Introduction}

The modern portfolio theory (MPT) portfolio optimisation problem is an ex-ante model of portfolio analysis; so the more accurate the forecasts of the portfolio inputs the better a fund manager's ability to take advantage of the future return and covariance structure the greater his/her ability to exploit the risk/return trade off. In other words to obtain the best performance in an ex-ante context the mean-variance model requires accurate forecasts of the future return and covariance structure. The simplest and most widely used method to generate such future inputs is to rely on their historic ex-post values. However, when such an approach has been examined in the real estate market the results tend to prove disappointing, Mueller and Laposa (1995), Myer and Webb (1991), Pagliari, et al (1995). Much of this failure of ex ante portfolio performance is due to estimation risk in the portfolio construction process, Lee and Stevenson (2000). The use of a portfolio selection procedure based on historical parameters that ignores the estimation risk is likely to produce sub-optimal results in subsequent periods. However, even the use of techniques such as the Bayes-Stein shrinkage estimator to reduce the degree of estimation error within the portfolio inputs has proved unsuccessful within the real estate portfolio, Lee and Stevenson (2000). One possible reason for the failure of ex-post data in accurately estimating the future ex-ante parameters of the portfolio problem is that previous studies have used historic time series data that is equally weighted. Equal weighting of the data, however, does not take account of the current state of the market. The use of the equally weighted historical data is thus unlikely to perform well in any subsequent periods, as the data is still reflecting market conditions that are no longer valid. The effect will be even more pronounced if the market moves from a rising to a falling phase and visa-versa. This argument is supported by the work of Lee (1998) who found that all three of the mean-variance portfolio parameters are unstable, especially in periods when the market changes dramatically. In a similar vein Sivtanides and Southard (2000) show that backward-looking risk measures, i.e. those based on historical data, are poor indicators of future volatility. A risk and return estimation scheme that gives greater weight to the most recent data would, therefore, seem desirable.

Previous studies, in the equity market, have shown that methods of volatility estimation that have weighted recent observations more heavily than older observations, such as exponentially weighted moving average (EWMA) techniques, or generalised autoregressive conditional heteroscedastic $(\mathrm{GARCH})$ models, are more successful at forecasting future volatility than those that do not weight the historic data. Comparative studies by Akgiray (1989), Vasilellis and Meade (1996), Brailsford and Faff (1993, 1996), Kroner (1996) and Walsh and Tsou (1998) all suggest that the EWMA and GARCH models are equally successful. However, Tse (1991) has shown that GARCH forecasts are slower to react to changes in volatility compared to EWMA techniques. In other words GARCH models are inferior to EWMA techniques when volatility changes abruptly. This would seem to imply that EWMA techniques might be preferable to GARCH models in estimating the parameters required for portfolio optimisation from historical data. However, using EWMA models is not without its problems. First, estimation of the smoothing parameter tends to involve a number of complicated steps, Walsh and Tsou (1998). Second, the values of the smoothing 
parameter results differ widely depending on time period and the market analysed ${ }^{1}$. As a result the performance estimation periods of various lengths and time periods of differing market conditions cannot be easily compared. To overcome these problems this study takes an alternative approach and uses returns data that is simply 'time-weighted'. That is, the methods adopted here simply use the length of the historical estimation period to weight the data and so to calculate the portfolio parameter to be used in subsequent evaluation periods. This is done to see if such a weighting scheme can offer improved performance over that based on un-weighted historical data.

The remainder of the paper is organised as follows. The next section discusses the methods used to time weight the historical data. Section three outlines the data used in the study and describes the research methodology. Results are presented and discussed in section four. Finally, section five concludes the paper and suggests directions for future research.

\section{Time Weighted Portfolio Optimisation}

\section{Time-weighted returns}

In the literature two time-weighed return schemes have been suggested as useful to estimate future portfolio parameters. The first is a form of the Fisher distributed lag model used by Ray and Nawrocki (1996) and the second the 'half-life' weighting scheme suggested by Sharpe (1995a).

The distributed lag approach suggested by Ray and Nawrocki (1996), assigns weights to the data at time period $\mathrm{t}$ by the value $\mathrm{w}_{\mathrm{t}}=\mathrm{t} / \Sigma \mathrm{T}$, where $\mathrm{T}$ is the number of observations over which the portfolio inputs are to be estimated and where the sum of the weights equals one. So, for example, if $\mathrm{T}=24$ the weight assigned to the most recent data (24/300) is $8 \%$, $\mathrm{t}-1(23 / 300)$ is $7.6 \%, \mathrm{t}-2(22 / 300)$ is $7.3 \%$ and so on. That is, when $\mathrm{T}=24$ the weight attached to the most recent observation is 24 times that of the most distant data point.

In contrast Sharpe's 'half-life' return weighting scheme weights the data by the value $2^{\wedge}(1 / h)$ times the weight assigned to the prior periods observation, where $h$ is some value between zero and T: where T is the number of time series data points. Thus, if $h$ equals zero no weighting is applied to the data and the resultant mean and covariance matrices are those used in the standard historic approach. For values greater than zero the method assigns greater weight to the most recent observation, such that half the weight of the current data is assigned to the observation $\mathrm{t}-h$. So, for example, if $h$ equals 1 the weight on the return for the most recent period $\mathrm{t}$ is $50 \%$, while that on period $\mathrm{t}-1$ is $25 \%, \mathrm{t}-2$ is $12.5 \%$ and so on, where the sum of the weights equal to one. That is, the weight on the returns is half that in each period compared with the most recent observation, hence the use of the term 'halflife'. Similarly, if the number of observations $\mathrm{T}$ is 24 and $h=\mathrm{T}$ the weight on the returns in

\footnotetext{
${ }^{1}$ For example Akgiray (1989) used smoothing parameters of 0.76 to 0.89 . Tse (1991) found a value of 0.86 proved the best. In contrast Walsh and Tsou (1998) found that the values ranged from 0.66 to 0.92, while Brailsford and Faff (1996) discovered that the smoothing parameter changed widely from 0 to 0.90 over the analysis period.
} 
each period is $2.85 \%$ greater than the predecessor and again the weight of the most distant observation $t-24$ is approximately half that of the data in period $t$. Thus, the method is only dependent on the number of time periods and the choice of weighting parameter $h$.

Both schemes of time weighting to better estimate the future values portfolio parameters can be justified on two counts. First simplicity, both methods are very easy to implement as the weighting of the returns depends solely on the number of time periods over which portfolio parameters are estimated. Second, giving greater weight to the most recent observations can be justified in a rational expectation context as it postulates a mode of behaviour that accords with common sense and is amply confirmed by simple observation, Shaw (1984). That is, it seems reasonable to assume that individuals adapt their expectations in the light of past experience and that the more distant the experience the lesser the effect such information has in forming those expectations. However, of the two time-weighted approaches, as the Sharpe 'half-life' technique applies a non-linear (exponential) weighting scheme to the returns data while the Ray and Nawrocki distributed lag approach uses a linear weighting scheme it may be supposed that the 'half-life' method would react more quickly to changes in the market and so produce better ex-ante performance.

\section{Portfolio Optimisation}

In matrix notation using both approaches the expected return vector $E(R)$ is given by the following equation:

$$
\mathrm{E}(\mathrm{R})=\mathrm{RW}^{\mathrm{T}}
$$

where $\mathrm{R}$ is the returns of each asset and $\mathrm{W}^{\mathrm{T}}$ is the transpose of the return-weight vector calculated by either the linear weighting scheme of Ray and Nawrocki (1996) or the nonlinear scheme of Sharpe (1995a).

While the variance-covariance matrix is calculated by:

$$
\mathrm{C}=\operatorname{Ddiag}(\mathrm{W}) \mathrm{D}^{\mathrm{T}}
$$

where $\operatorname{diag}(\mathrm{W})$ is a matrix of zeros with its diagonal elements derived from the time dependent weights. This matrix is pre-multiplied by $\mathrm{D}$ and post-multiplied by the transpose of $\mathrm{D}$, a matrix of deviations of the returns from the weighted mean return vector calculated by equation $1^{2}$.

Once set up in this form, such a portfolio problem can then be easily solved using the EXCEL add-in Solver (Byrne and Lee, 1994a, 1994b), or by any other optimisation software that can take the mean return vector and the covariance matrix as inputs. This shows that it is very easy to use the time-weighted data to estimate the optimal holdings in the portfolio problem, as the portfolio optimisation process is identical for the weighted and un-weighted data. Indeed, the only differences between the weighted and un-weighted

\footnotetext{
${ }^{2}$ see Sharpe (1995b) for more details using the matrix programming language MATLAB
} 
inputs are the values of weight matrix (W), which in the case of un-weighted data are a series of ones.

\section{Data and Research Design}

\section{Data}

The data used in this study are the monthly total returns for the three sectors: Office, Retail and Industrial property extracted from the Investment Property Databank Monthly Index (IPDMI). The data used covering the period 1987:1 to 2000:12, a total of 168 observations. The property sector data divided into three 'super regions': London, Southern England and 'the North' (the remaining peripheral areas). The use of nine market segments is necessary for three reasons. First, limiting the number of investment opportunities to the three by three sector/regions is done to minimise potential optimisation errors that can arise when semi-definite covariance matrices are estimated with small time series samples, Ong and Ranasinghe (2000). Second, the use of real estate data, from the direct property market, in the portfolio problem presents particular problems due to the non-normality in the data, as normality is a central principle required for the appropriate application of MPT (Byrne and Lee, 1996). For example, Lizieri and Ward (2000) find that the various sub-markets of the IPDMI do not conform to the normal distribution due to the presence of a high proportion of zero returns and too few larger, negative and positive returns. The authors attribute this to the thinly traded nature of the direct property market where new information is infrequent and only slowly impounded into valuations, upon which capital returns are based. However, even de-smoothing the time series failed to improve the distributional fit of the data. Therefore de-smoothing the data would seem to serve no purpose. Further, Byrne and Lee $(1996,1999)$ show that portfolio optimisation using Mean Absolute Deviation (MAD) as the measure of risk, to account for the non-normality in the property data, produces portfolio weights similar, if not identical, to those produce by MPT. This implies the mean-variance of MPT approach is robust to departures from normality within the data. In addition, Walsh and Tsou (1998) show that while the non-trading effect evident in thinly traded equities has the effect of reducing forecast ability, this is more than compensated by the diversification effect from the use of indices. Finally, Eichholtz et al (1995) argue that such a three-property type and three 'super regional' classification provides a viable portfolio investment strategy for investors in the UK, with little to be gained from a more refined classification scheme. In other words the use of a small number of real estate indices with un-smoothed returns in the portfolio optimisation process may be acceptable.

Table 1 and Figure 1, shows the performance of the nine sector/regional indices for the overall period of analysis and for seven 24-month sub periods. Overall the Industrial sector showed the greatest level of returns, while the Retail sector displayed the lowest risk. In contrast, the Office sector generally showed the worst returns and highest levels of risk. As is to be expected, the sector/region that performs 'best' in each period changes from subperiod to sub-period. For example, in period 1 from 1987: 1 to 1988:12, the market boom, the highest returns were earned in Industrial properties, especially the further away from London, closely followed by the London Office market. In contrast, the lowest risk 
was attained by the Retail sector, especially in the Rest of the UK. However, in period 2, 1989:1 to 1990:12, the period when the market performance shifted from boom to bust, the highest returns were achieved by the Office sector in the Rest of the UK, while the Retail sector, especially in the South showing the worst level of performance. Then in period 3, as the market moved out of the trough, the Office sector displayed negative performance while the Industrial and Retail sectors showed positive performance, especially the further away from London. This switching around in performance continues into the seventh and final period, 1999:1 to 2000:12, when, once again, the Industrial sector showed the greatest returns but this time the Office sector displayed the lowest risk. In all, the data presents a picture of risk and return instability found in previous studies, see Lee (1998). Indeed, statistical tests of the data, not shown here, reject stationarity in the mean return vector and the variance/covariance matrix in the all sub-periods, both adjacent and non-adjacent (see Lee, 1998 for an explanation of the tests). Consequently, it would be no surprise that exante portfolio parameters derived from historical un-weighted data should period perform badly in subsequent periods. The use of the time-weighted returns data may prove beneficial, as it should react more quickly to changes in current market conditions.

\section{Research Design}

In order to test the effectiveness of the time-weighed ex-post optimisation, in subsequent periods efficient portfolios were formed using data from the past and the portfolio weights held into the next period, as in the approach of Pagliari, et al (1995) However, unlike Pagliari, \& al, who analysed the whole efficient frontier in each period, only one ex-post portfolio is examined here, the Sharpe tangency portfolio. This is done for a number of reasons. First, since most risk-averse investors have a fundamental interest in achieving the best portfolio risk/return trade-off, the Sharpe tangency portfolio is particularly attractive as this portfolio is the one offering the highest ex-post mean return per unit risk. Second, the composition of the Sharpe tangency portfolio is independent of the investors' risk preferences (Tobin, 1958), consequently such a portfolio is the most desirable to all investors. Third, the work of Lee and Stevenson (2000) shows that the ex-post Sharpe tangency portfolio performed best in comparison to the alternative investment strategies designed to account for estimation error in ex-ante portfolio inputs derived from unweighted historical data. Thus, the performance of the time-weighted portfolio strategies used here can be compared with the 'best' performing un-weighted investment strategy identified by Lee and Stevenson (2000). Finally, comparisons between different efficient frontiers are practically difficult to evaluative and cannot be subjected to statistical testing. In comparison Sharpe tangency portfolios are easy to compare and test for statistical significance using the Jobson and Korkie (JK) (1981) Z statistic.

The weights of the ex-post Sharpe tangency portfolio are identified by the following maximisation problem:

$$
\operatorname{Max} \theta=\frac{\bar{r}_{p}-r_{f}}{\sigma_{p}^{2}}
$$


where: $\bar{r}_{p}$ is the expected return on portfolio $p, r_{f}$ is the risk-free rate of return and $\sigma_{p}^{2}$ is the variance of the portfolio. In conducting the analysis the risk-free rate of return was assumed to be zero for simplicity.

To test the performance of the two time-weighted approaches and that of the un-weighted investment strategy, the performance the three strategies were compared against the performance of a naï ve equal weighted portfolio and that of the market benchmark as represented by the IPDMI. The naï ve portfolio represents the simplest buy-and-hold strategy that could be followed by those investors with no return forecasting ability. In contrast, the returns of the IPDMI are used as the benchmark of property market performance by most investors in the market, Morrell (1995).

To evaluate relative performance of each real estate investment strategy against the two benchmarks, the Sharpe performance index, $\left(\mu-R_{f}\right) / \sigma$, i.e. the ratio of mean excess return to standard deviation, is used. In conducting the tests, the risk-free interest rate, $R_{f}$, is set to zero. The significance of the difference in Sharpe performance of any two portfolios a and $\mathrm{b}$ can then be tested using the $\mathrm{Z}$ statistic (Jobson and Korkie, 1981):

$$
Z=\frac{\sigma_{a}\left(\mu_{b}-R_{f}\right)-\sigma_{b}\left(\mu_{a}-R_{f}\right)}{\sqrt{\Theta}}
$$

where $\mu_{\mathrm{a}}, \mu_{\mathrm{b}}$ are the mean returns of portfolios $a$ and $b$ and $\sigma_{\mathrm{a}}, \sigma_{b}$ and $\sigma_{a b}$ are estimates of the standard deviation and covariances of the excess returns of the two portfolios over the evaluation period and where $\Theta$ is calculated as follows:

$$
\Theta=\frac{1}{\mathrm{~T}}\left[2 \sigma_{\mathrm{a}}^{2} \sigma_{\mathrm{b}}^{2}-2 \sigma_{\mathrm{a}} \sigma_{\mathrm{b}} \sigma_{\mathrm{ab}}+\frac{1}{2} \mu_{\mathrm{a}}^{2} \sigma_{\mathrm{b}}^{2}+\frac{1}{2} \mu_{\mathrm{b}}^{2} \sigma_{\mathrm{a}}^{2}-\frac{\mu_{\mathrm{a}} \mu_{\mathrm{b}}}{2 \sigma_{\mathrm{a}} \sigma_{\mathrm{b}}}\left(\sigma_{\mathrm{ab}}^{2}+\sigma_{\mathrm{a}}^{2} \sigma_{\mathrm{b}}^{2}\right)\right]
$$

where $\mathrm{T}$ is the number of observations. Jobson and Korkie (19981) show that the test statistic $\mathrm{Z}$ is approximately normally distributed with a zero mean and a unit standard deviation for large samples. A significant $\mathrm{Z}$ statistic would reject the null hypothesis of equal risk-adjusted performance and would suggest that one of the investment portfolio strategies outperforms the other. Note that the statistical power of the test is low: for a $5 \%$ significance level, it fails to reject a false null $85 \%$ of time (Jorion 1992). Thus, observing a statistically significant $\mathrm{Z}$ score between two portfolios can be seen as a strong evidence of a difference in risk-adjusted performance.

The ex-post estimation period was set at 24 months with the inputs re-estimated every 6, 12 and 24 months. That is the first 24 months of data (1987:1 to 1988:12) were used to calculate the portfolio inputs for the first ex-post optimisation. These weights were then used to purchase a portfolio on January 1989. This portfolio was then held for 6 (12 or 24) months in an ex-ante portfolio after which the optimum ex-post portfolio parameters were then re-estimated using the updated 24-month period returns. In other words the portfolio optimisation used a 24-month rolling window to calculate the means, variances and covariances, with the updated portfolio holdings derived from this new data. The portfolio 
rebalanced to the new allocations and held for 6 (12 or 24) months before the process was repeated; the analysis performed with a variety of values for $h$, the 'half-life' weighting factor. The weights chosen were $0,1,6,12,18$ and 24 . The half-life time-weights therefore, cover the whole range of potential return weighting values, from no weight at all $(\mathrm{h}=0)$, followed by the one which weights the most recent observation the most, a weight of 1 , through to the one with least impact, i.e. when $\mathrm{h}=\mathrm{T}$ (i.e., $\mathrm{h}=24$ ). The portfolio investment strategies simulated from 1989:1 to 2000:12 to provide a true out of sample performance evaluation, as it uses the prior 24 months of the data to estimate the new portfolio asset holdings at the end of each 6,12 or 24-month rebalancing period.

\section{Results}

\section{Overall Performance}

The results of the portfolio simulations for the overall the period from 1989:1 to 2000:12 are presented in Table 2. The table shows the terminal wealth of $£ 100$ invested in December 1988, i.e. after the first ex-post optimisation, the time weighted (geometric) mean return, the arithmetic mean monthly returns and the monthly standard deviations. In addition the reward to variability ratio or Sharpe Ratio (Sharpe, 1966, 1994) is provided in order to show the risk-adjusted performance of the various strategies. The Sharpe Ratio shows the return per unit risk and so the higher the ratio, the greater the risk-adjusted performance. Finally columns 7 and 8 of Table 2 present the JK Z statistics, which test the significance or otherwise of the alternative investment strategies against the two benchmarks of performance.

Table 2 has a number of features of interest. First, all the three investment strategies, i.e. the un-weighted, linearly weighted or the half-life methods, achieved higher terminal wealth positions than either the market benchmark or the naï ve strategy. For instance, the unweighted return portfolio, rebalanced every six months, showed a terminal wealth of $£ 325.3$ compared with only $£ 268.5$ and $£ 282.4$ for the IPDMI and the naï ve portfolio benchmarks respectively. The terminal wealth figures generally declined the longer the time before rebalancing, except for the 'half-life' strategy with $\mathrm{h}=1$, which showed greater performance when the portfolio is rebalanced every 24 -months. Indeed when $\mathrm{h}=1$, the 24month rebalancing strategy shows a terminal wealth $1 / 3^{\text {rd }}$ greater than that of the market benchmark. The greater terminal wealth figures were reflected in the higher geometric and arithmetic means of all investment strategies in comparison with the two benchmarks of performance. For instance, the un-weighted return portfolio, rebalanced every six months, showed a geometric return of $0.822 \%$ per month compared with the IPDMI's performance of $0.689 \%$ and the naï ve portfolios $0.724 \%$ per month. The linear adaptive approach showing comparable performance with almost the same geometric mean. In contrast, the results for the half-life approach when $\mathrm{t}=1$ and $\mathrm{h}=24$ are somewhat higher than the unweighted or linearly weighted approaches, at $0.856 \%$ and $0.826 \%$ per month respectively.

Secondly, the higher return performance was achieved with only a marginal increase in risk (standard deviation). Indeed, tests of the equality of variances (not reported here), using the Brown-Forsythe modified Levene test (Brown and Forsythe, 1974) show that there is no 
significant difference in the risks of the alternative investment strategies and either the IPDMI or the naï ve portfolio investment benchmarks. Consequently all the investment strategies, except for the half-life approach with $\mathrm{h}=1$, reviewed every 12 months, achieved significantly higher Sharpe Ratios in comparison with the IPDMI and the naï ve portfolio as measured by the JK statistics shown in columns 7 and 8 of Table 2 .

Finally, as is to be expected, as the review period decreases the average return performance improves. For instance, the returns of the un-weighted strategy increases from $0.782 \%$ per month, with a 24 -month review period, to $0.805 \%$ per month for the 12 month rebalancing period, $0.822 \%$ per month for the six-month review period, an increase of 40 basis points. However, in no case are these increases significant, at the usual levels, based on t-tests (not reported). In addition, reducing the review period has only a slight impact in reducing portfolio risk. This implies that increasing the frequency of the review period may have little impact on risk-adjusted return performance. Indeed JK statistics (not reported) show that there is no difference in Sharpe performance between the methods and the frequency of review, at the usual levels of significance, except for the half-life approach with $h=1$ reviewed every 12 months. Thus any benefit from more frequent reviews would be easily eliminated by increased transaction costs.

\section{Sub-period Analysis}

Whilst pleasing, the results need to be analysed in more depth to see if the investment strategies achieved these results in the time when they were most needed i.e. when the market turned, as in periods 2, 3 and 4, rather than when the market was in much calmer times such as period 5, 6 and 7,(see Figure 1). The ex-ante performance of the investment strategies was, therefore, broken down into six 24-month sub-periods as shown in Table 3.

It is clear from Table 3 that all the investment strategies showed exceptionally good return performance in period 2, when the market moved from a peak to trough, see Figure 1. Most encouragingly are the results of the 'half-life' method $(\mathrm{h}=1)$ rebalanced every six or 12 months, which should react the fastest. As can be seen, this approach showed the greatest average returns in period 2, $0.63 \%$ per month, almost double that of the market at $0.38 \%$ per month. The un-weighted, the linear adaptive approach and 'half-life' approach, with $\mathrm{h}=24$, showing comparable levels of return performance over the different review periods. The alternative investment strategies tended to show lower return performance the greater the review period, as is to be expected. Importantly, this greater return performance was coupled with lower risk than either the naï ve portfolio or the market benchmark, except for the half-life method with $\mathrm{h}=1$.

However, it is the performance of all the approaches in period 3, during the market trough, that the benefits of all the investment strategies show their true value. The investment strategies all showing positive average returns compared with the negative performance of the market and the naï ve investment strategy. However, to achieve this level of performance would have meant selling out of the Office market, especially in London and the Southeast and concentrating the holdings of the fund in the Retail and Industrial sectors in 
the Rest of the UK, a strategy, which although desirable, may not have been achievable in practice.

This striking performance by all the alternative ex-post investment strategies was maintained in period 4, as the market bounced back, with all the strategies out-performing the two portfolio benchmarks by a considerable margin with only a slight increase in risk. This is especially impressive, as it must be remembered that the Sharpe tangency portfolio optimisations were based on data from period 3, which is a period of market performance that is in stark contrast to that in period 4 , see Table 1.

In contrast, when the market is performing reasonable well, as in periods 5 and 6 , or when the market reversal is less severe, as in period 7, the approaches only offered a marginal improvement in average returns, with little difference in risk, compared with the two benchmarks of performance. In other words, when the market doing well, or there is relative calm in the market, all sectors and regions tend to do well, and as a consequence, a simple (naï ve) diversification strategy offers reasonable levels of return compared with the market.

Finally, when comparing the various investment strategies. it is clear from Tables 2 and 3 that the un-weighted and linear adaptive method tends to produce similar levels of performance. In contrast, the half-life approach, at all review periods and weighting, shows the highest returns overall and in almost all sub-periods, except for period 4 when its performance is nearly the same as the best performing approach. The extent of time weighting (i.e. the value of $h$ ) and the length of the rebalancing period changes, however, as the market moves from turbulent to calmer times. For instance in period 2 and 3 the best strategy needs the greatest weighting scheme, i.e. $\mathrm{h}=1$, with the portfolios rebalanced every six-months. However, during periods 5-7 when the market is less turbulent, although the half-life method with $\mathrm{h}=1$ still achieves the highest returns, the re-balancing period tends to increase, as would be expected. Nonetheless, in the long run all the ex-post Sharpe tangency portfolio methods provided much higher levels of return over that of the market benchmark, or a naive portfolio investment strategy, at little increase in risk. Hence, the investment strategies showed a significant improvement in risk-adjusted performance. More importantly, this improved performance was at a time when the fund manager needed it most, i.e. in periods 2,3 and 4, especially the half-life method with $\mathrm{h}=1$. In other words all the approaches, but especially the time-weighted methods, would have provided the fund manager with the 'right' market signals at the turning points in the market.

\section{Conclusions}

The results in Tables 2 and 3 show that all the optimal ex-post estimation strategies used to derive the portfolio inputs for ex-ante portfolios out-performed a naï ve investment strategy and the market benchmark, either using weighted or un-weighted returns data. The strategies all show greater terminal wealth and average return levels, at the cost of only a slight increase in risk, than that of the benchmarks of performance. Consequently, all the strategies showed significantly greater, risk adjusted performance. More importantly, the ex-post optimum investment strategies worked particularly well when they were most 
needed, i.e. during periods of reversals in the market. This is particularly noticeable in the case of the non-linear 'half-life' method, especially when $\mathrm{h}=1$, which, by construction, should in any case react fastest to changes in market conditions. However, even in periods of less market volatility the half-life method still shows greater performance than the market benchmark, although a simple diversification strategy would have performed equally as well.

In line with the work of Lee and Stevenson (2000), in the long run, intensifying the frequency of the review period leads to only a minor increase in return performance that would be easily eliminated by the increased transaction costs compared with, say, a 24-month rebalancing strategy; the exception is for the 'half-life' procedure when $\mathrm{h}=1$, which showed slightly lower performance the shortest review period.

Possible extensions of this work would be investigate the effect of shortening the ex-post time horizon over which the portfolio weights are estimated, thereby, hopefully making the results even more sensitive to changes in recent market conditions. This approach, however, has the disadvantage that the number of time periods used to estimate the portfolio inputs will be less than the number of asset classes, leading to problems of rank in the covariance matrix and the inadmissibility of its use in the optimisation, see Ong and Ranasinghe (2000). The effects of transaction costs and taxes on the gains from diversification within the real estate portfolio could also be used to extend the analysis. However, undertaking such an analysis would involve the incorporation of a number of assumptions concerning investor behaviour. In particular, assumptions would have to be made concerning the level of movement that would be allowed within each specified holding period. For example, in the analysis above it would be totally unrealistic to assume that changes in the allocations could occur immediately, especially within the six-month review period. It would, therefore, be necessary to place restrictions on the percentage change that would be feasible within a specified holding period and to assume that such a change occurred gradually over the same period. However, the results above in Table 2 indicate that there may be little benefit to be gained by reducing the review period and so increasing the transaction costs over the long run. 


\section{References}

Akgiray, V. (1989) Conditional Heteroscedasticity in Time Series of Stock Returns: Evidence and Forecasts, Journal of Business, 62, 55-80.

Brailsford, T. and Fraff, R. (1993) Modelling Australian, Stock Market Volatility, Australian Journal of Management, 18, 109-132.

Brailsford, T. and Fraff, R. (1996) An Evaluation of Volatility Forecasting Techniques, Journal of Banking and Finance, 20, 419-438.

Brown, M.B. and Forsythe, A.B. (1974) Robust Tests For the Equality of Variances, Journal of the American Statistical Association, 69, 364-367.

Byrne, P. and Lee, S.L. (1994a) Computing Markowitz Efficient Frontiers Using a Spreadsheet Optimiser, Journal of Property Finance, 5, 1, 58-66

Byrne, P. and Lee, S.L. (1994b) Real Estate Portfolio Analysis Using a Spreadsheet Optimiser, Journal of Property Finance, 5, 4, 19-31.

Byrne, P. and Lee, S.L. (1996) Real Estate Portfolio Analysis under Conditions of NonNormality: The Case of NCREIF, The Journal of Real Estate Portfolio Management, $\mathbf{3}$, 1, 37-46.

Byrne, P. and Lee, S.L. (1999) The Place of Property in an Australian Multi-Asset Portfolio: A Comparison of the MPT and MAD Optimisation Methods, Australian Land Economics Review, 5, 1, 21-28.

Eichholtz, P. M. A., Hoesli, M., MacGregor, B. D. and Nanthakumaran, N. (1995) Real Estate Diversification by Property-type and Region, Journal of Property Finance, 6, 3, 39-62.

Jobson, J.D. \& Korkie, B. (1981). Performance Hypothesis Testing with the Sharpe and Treynor Measures, Journal of Finance, 36, 888-908.

Jorion, P. (1992) Portfolio Optimisation in Practice, Financial Analysts Journal, JanuaryFebruary, 68-74.

Kroner, K. F. (1996) Creating and Using Volatility Forecasts, Derivatives Quarterly, Winter, 39-53.

Lee, S.L. (1998) The Inter-Temporal Stability of Real Estate Returns: An Empirical Investigation, Working Papers in Land Management and Development, 04/98, pp. 23. 
Lee, S.L. and Stevenson, S. (2000) Real Estate Portfolio Construction and Estimation Risk, A Paper Presented at the 7th European Real Estate Society Conference, Bordeaux, France, 14-16 June 2000

Lizieri, C. and Ward, C.W.R. (2000) Commercial Real Estate Return Distributions, A Review of Literature and Empirical Evidence, in Knight, J. and Satchell, S. (eds.), Return Distributions in Finance, Butterworths-Heinemann, Oxford.

Morrell, G. (1995) Property Indices: A Coming of Age? Journal of Property Valuation \& Investment, 13, 3, 8-21.

Mueller, G. R. and Laposa, S.P. (1995) Property-Type Diversification in Real Estate Portfolios: Size and Return Perspective, The Journal of Real Estate Portfolio Management, 1,1, 39-50.

Myer, F.C.N. and Webb, J.R. (1991) Estimating Allocations for Mixed-Asset Portfolios Using the Bootstrap Technique, Paper presented at the American Real Estate Society Meeting, Sarasota, Florida.

Ong, S-E. and Ranasinghe, M. (2000) Portfolio Variance and Correlation Matrices, Journal of Portfolio Management, 6, 1, 1-6.

Pagliari, J.L., Webb, J.R. and Del Casino, J.J. (1995) Applying MPT to Institutional Real Estate Portfolios: The Good the Bad and the Uncertain, The Journal of Real Estate Portfolio Management, 1,1, 67-88.

Ray, K. and Nawroki, D. (1996) Linear Adaptive Weights and Portfolio Optimization, http:/www.handholders.com/old/raylam.html.

Shaw, G.K. (1984) Rational Expectations: An Elementary Exposition, St. Martins Press, New York.

Sharpe, W.F. (1966) Mutual Fund Performance, Journal of Business, 39, (Jan), 119-138. (1994) The Sharpe Ratio, Journal of Portfolio Management, Fall, 49-58. . (1995a) The Style and Performance of Large Seasoned U.S. Mutual Funds, 1985-1994, http://www.stanford.edu/ wfsharpe/art/ls100/ls100.html. March. (1995b) WCOV, http//www.stanford.edu/ wfsharpe/mat/wcoc.text.html, November 2.

Sivitanides, P. and Southard, J. (2000) Does Historical Volatility Capture True Risk in Real Estate, A Paper Presented at the ARES Conference, Santa Barbara, California.

Tobin, J. (1958) Liquidity Preference as Behavior Toward Risk, Review of Economic Studies, February. 
Tse, Y. (1991) Stock Return Volatility in the Tokyo Stock Exchange, Japan and the World Economy, 3, 285-298.

Vasilellis, G. and Meade, N. (1996) Forecasting Volatility for Portfolio Selection, Journal of Business Finance and Accounting, 23, 125-143.

Walsh, D.M. and Tsou, G.Y. (1998) Forecasting Index Volatility: Sampling and Interval and Non-trading Effects, Applied Financial Economics, 8, 477-485. 
Figure 1: The Performance of the IPDMI 1987:1 to 2000:12

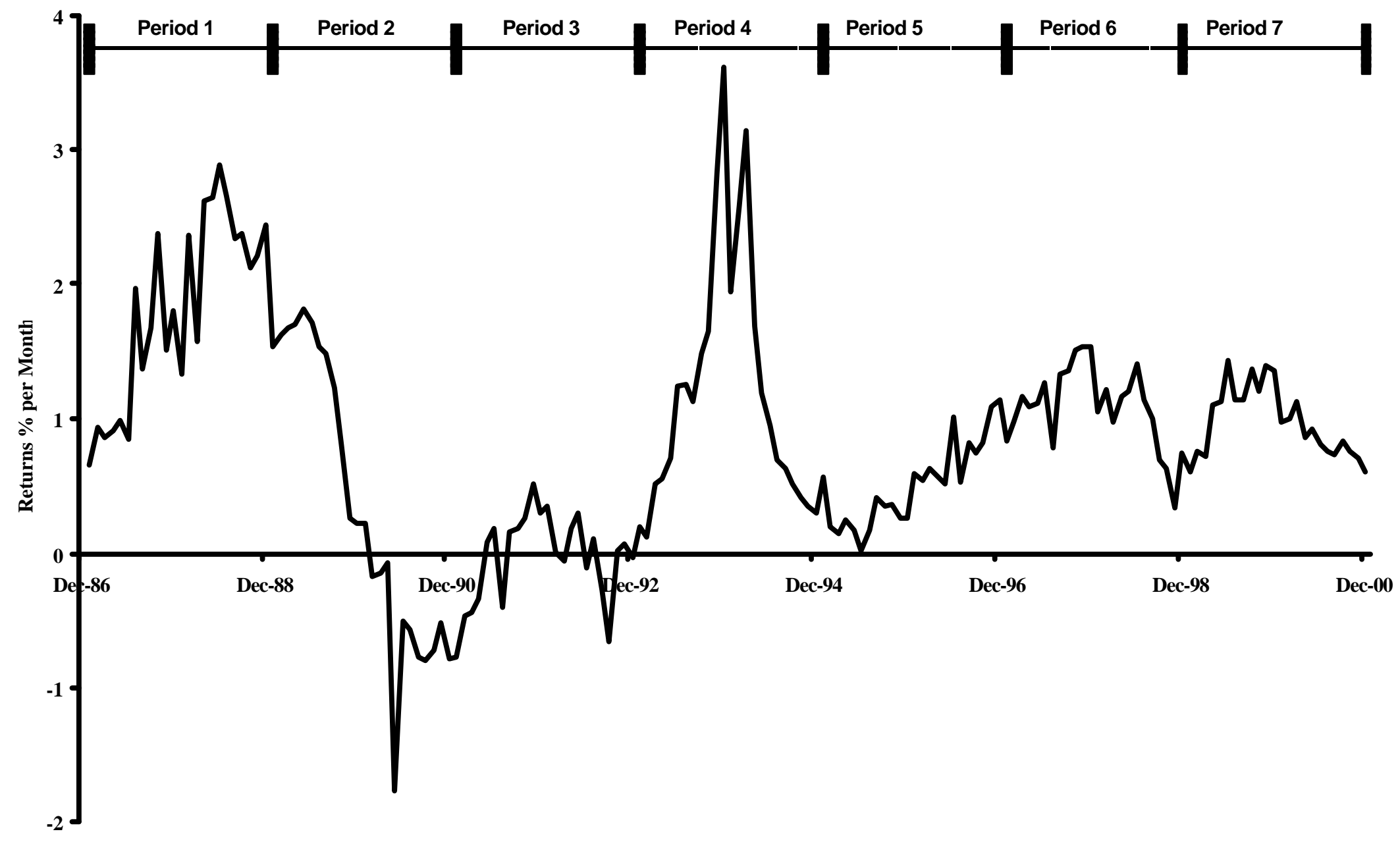


Table: 1 The Risk and Return Characteristics of Sector and Regional Indices Per cent per Month 1987:1 to 2000:12

\begin{tabular}{|c|c|c|c|c|c|c|c|c|c|c|c|c|c|c|c|c|}
\hline \multirow{2}{*}{$\begin{array}{l}\text { Period } \\
\text { Sector/Region }\end{array}$} & \multicolumn{2}{|c|}{ Period 1} & \multicolumn{2}{|c|}{ Period 2} & \multicolumn{2}{|c|}{ Period 3} & \multicolumn{2}{|c|}{ Period 4} & \multicolumn{2}{|c|}{ Period 5} & \multicolumn{2}{|c|}{ Period 6} & \multicolumn{2}{|c|}{ Period 7} & \multicolumn{2}{|c|}{ Overall } \\
\hline & Mean & SD & Mean & SD & Mean & SD & Mean & SD & Mean & SD & Mean & SD & Mean & SD & Mean & SD \\
\hline \multicolumn{17}{|l|}{ Retail } \\
\hline London & 1.89 & 1.13 & 0.02 & 0.83 & 0.06 & 0.45 & 1.16 & 0.96 & 0.66 & 0.40 & 1.27 & 0.53 & 0.85 & 0.34 & 0.85 & 0.94 \\
\hline South East & 1.44 & 0.88 & 0.09 & 0.84 & 0.23 & 0.46 & 1.23 & 1.06 & 0.32 & 0.39 & 0.89 & 0.40 & 0.73 & 0.38 & 0.70 & 0.82 \\
\hline Rest of UK & 1.36 & 0.55 & 0.10 & 0.81 & 0.42 & 0.43 & 1.41 & 0.99 & 0.52 & 0.35 & 1.10 & 0.37 & 0.76 & 0.39 & 0.81 & 0.75 \\
\hline \multicolumn{17}{|l|}{ Office } \\
\hline London & 2.20 & 1.03 & 0.17 & 1.34 & -1.13 & 0.57 & 1.02 & 0.98 & 0.64 & 0.30 & 1.18 & 0.47 & 1.36 & 0.33 & 0.78 & 1.26 \\
\hline South East & 1.49 & 1.06 & 0.45 & 1.39 & -0.48 & 0.45 & 1.12 & 1.12 & 0.37 & 0.42 & 1.18 & 0.33 & 1.08 & 0.27 & 0.74 & 1.03 \\
\hline Rest of UK & 2.00 & 1.45 & 1.16 & 1.65 & -0.07 & 0.43 & 1.09 & 1.10 & 0.42 & 0.34 & 0.87 & 0.23 & 0.98 & 0.26 & 0.92 & 1.12 \\
\hline \multicolumn{17}{|l|}{ Industrial } \\
\hline London & 2.14 & 1.54 & 0.76 & 1.63 & 0.30 & 0.59 & 1.16 & 1.01 & 0.62 & 0.31 & 1.31 & 0.40 & 1.44 & 0.45 & 1.10 & 1.13 \\
\hline South East & 2.20 & 1.02 & 0.96 & 1.28 & 0.22 & 0.57 & 0.94 & 1.00 & 0.39 & 0.50 & 1.27 & 0.37 & 1.28 & 0.33 & 1.04 & 1.00 \\
\hline Rest of UK & 2.57 & 1.18 & 0.91 & 1.41 & 0.34 & 0.56 & 1.41 & 0.99 & 0.58 & 0.36 & 1.04 & 0.25 & 1.10 & 0.32 & 1.14 & 1.06 \\
\hline
\end{tabular}

Source: IPDMI 
Table 2: Overall Out-of-Sample Performance of the Time Weighted Investment Strategies 1989:1 to 2000:12 24-Month Estimation Period, Rebalanced Every 6, 12 and 24 Months

\begin{tabular}{|c|c|c|c|c|c|c|c|}
\hline Investment Strategy & $\begin{array}{c}\text { Terminal } \\
\text { Wealth } \mathfrak{f}^{\prime} \mathbf{s}\end{array}$ & $\begin{array}{c}\text { Geometric } \\
\text { Mean \% }\end{array}$ & $\begin{array}{c}\text { Arithmetic } \\
\text { Mean \% }\end{array}$ & $\begin{array}{c}\text { Standard } \\
\text { Deviation \% }\end{array}$ & $\begin{array}{c}\text { Sharpe } \\
\text { Ratio }\end{array}$ & $\begin{array}{l}\text { JK Z Test } \\
\text { v's IPDMI } \\
\end{array}$ & $\begin{array}{l}\text { JK Z Test } \\
\text { v's Naive }\end{array}$ \\
\hline IPDMI & 268.5 & 0.689 & 0.692 & 0.777 & 0.890 & $\mathrm{n} / \mathrm{a}$ & \\
\hline $\begin{array}{l}\text { Naï ve Investment } \\
6 \text { month rebalancing }\end{array}$ & 282.4 & 0.724 & 0.727 & 0.781 & 0.930 & -2.683 & $\mathrm{n} / \mathrm{a}$ \\
\hline Un-weighted & 325.3 & 0.822 & 0.825 & 0.760 & 1.086 & -6.413 & -4.828 \\
\hline Linear Adaptive & 324.7 & 0.821 & 0.824 & 0.767 & 1.075 & -5.598 & -4.194 \\
\hline Half-life $h=1$ & 341.4 & 0.856 & 0.860 & 0.812 & 1.058 & -5.026 & -4.116 \\
\hline Half-life $h=24$ & 326.9 & 0.826 & 0.829 & 0.762 & 1.087 & -6.273 & -4.770 \\
\hline \multicolumn{8}{|l|}{12 month rebalancing } \\
\hline Un-weighted & 317.1 & 0.805 & 0.807 & 0.768 & 1.052 & -5.450 & -3.767 \\
\hline Linear Adaptive & 320.8 & 0.813 & 0.816 & 0.768 & 1.062 & -5.187 & -3.715 \\
\hline Half-life $h=1$ & 316.6 & 0.804 & 0.807 & 0.871 & 0.926 & $-1.105 *$ & $0.230^{*}$ \\
\hline Half-life $h=24$ & 319.2 & 0.809 & 0.812 & 0.772 & 1.052 & -5.206 & -3.593 \\
\hline \multicolumn{8}{|l|}{24 month rebalancing } \\
\hline Un-weighted & 307.1 & 0.782 & 0.785 & 0.806 & 0.975 & -3.049 & $-1.417 *$ \\
\hline Linear Adaptive & 312.9 & 0.795 & 0.793 & 0.797 & 1.001 & -4.834 & -2.098 \\
\hline Half-life $h=1$ & 359.6 & 0.893 & 0.896 & 0.803 & 1.116 & -7.818 & -7.089 \\
\hline Half-life $h=24$ & 311.4 & 0.792 & 0.795 & 0.798 & 0.996 & -3.703 & -2.048 \\
\hline
\end{tabular}

Notes: 1 The Results for the $\mathrm{h}=6,12$ and 18 are not reported as they are essentially the same as for $\mathrm{h}=24$.

2. A negative indicates that the IPDMI or the Naï ve portfolio was outperformed by the alternative investment strategy.

3 All the JK statistics are all significant at the 5\% level, except those marked *. 
Table 3: Sub-period Performance of the Time Weighted Investment Strategies 1989:1 to 2000:12 24-Month Estimation Period, Rebalanced Every 6, 12 and 24 Months

\begin{tabular}{|c|c|c|c|c|c|c|c|c|c|c|c|c|}
\hline \multirow[b]{2}{*}{ Investment Strategy } & \multicolumn{2}{|c|}{ Period 2} & \multicolumn{2}{|c|}{ Period 3} & \multicolumn{2}{|c|}{ Period 4} & \multicolumn{2}{|c|}{ Period 5} & \multicolumn{2}{|c|}{ Period 6} & \multicolumn{2}{|c|}{ Period 7} \\
\hline & Return & Risk & Return & Risk & Return & Risk & Return & Risk & Return & Risk & Return & Risk \\
\hline Market & 0.38 & 1.08 & -0.03 & 0.33 & 1.24 & 0.97 & 0.51 & 0.31 & 1.09 & 0.30 & 0.98 & 0.26 \\
\hline Naï ve & 0.51 & 1.15 & -0.01 & 0.31 & 1.17 & 0.97 & 0.50 & 0.29 & 1.12 & 0.30 & 1.06 & 0.26 \\
\hline \multicolumn{13}{|l|}{6 month rebalancing } \\
\hline Un-weighted & 0.42 & 0.92 & 0.31 & 0.55 & 1.44 & 1.04 & 0.57 & 0.31 & 1.10 & 0.31 & 1.01 & 0.28 \\
\hline Linear Adaptive & 0.42 & 0.95 & 0.34 & 0.56 & 1.44 & 1.06 & 0.53 & 0.31 & 1.09 & 0.31 & 1.11 & 0.27 \\
\hline Half-life $h=1$ & 0.63 & 1.39 & 0.44 & 0.44 & 1.30 & 1.00 & 0.54 & 0.36 & 1.17 & 0.30 & 1.08 & 0.23 \\
\hline Half-life $h=24$ & 0.43 & 0.94 & 0.32 & 0.56 & 1.44 & 1.04 & 0.56 & 0.31 & 1.10 & 0.31 & 1.12 & 0.28 \\
\hline \multicolumn{13}{|l|}{12 month rebalancing } \\
\hline Un-weighted & 0.32 & 0.88 & 0.26 & 0.51 & 1.42 & 1.01 & 0.53 & 0.34 & 1.21 & 0.33 & 1.11 & 0.29 \\
\hline Linear Adaptive & 0.34 & 0.87 & 0.34 & 0.56 & 1.43 & 1.04 & 0.48 & 0.34 & 1.20 & 0.33 & 1.10 & 0.28 \\
\hline Half-life $h=1$ & 0.40 & 1.44 & 0.37 & 0.46 & 1.19 & 1.12 & 0.60 & 0.28 & 1.19 & 0.38 & 1.09 & 0.37 \\
\hline Half-life $h=24$ & 0.30 & 0.88 & 0.30 & 0.53 & 1.43 & 1.03 & 0.52 & 0.34 & 1.22 & 0.33 & 1.10 & 0.29 \\
\hline \multicolumn{13}{|l|}{24 month rebalancing } \\
\hline Un-weighted & 0.17 & 0.98 & 0.23 & 0.49 & 1.41 & 0.98 & 0.53 & 0.34 & 1.24 & 0.38 & 1.15 & 0.28 \\
\hline Linear Adaptive & 0.16 & 0.96 & 0.34 & 0.56 & 1.39 & 0.97 & 0.52 & 0.35 & 1.24 & 0.38 & 1.13 & 0.27 \\
\hline Half-life $h=1$ & 0.58 & 1.21 & 0.34 & 0.56 & 1.31 & 0.96 & 0.58 & 0.29 & 1.26 & 0.35 & 1.29 & 0.30 \\
\hline Half-life $h=24$ & 0.16 & 0.96 & 0.28 & 0.52 & 1.40 & 0.97 & 0.56 & 0.35 & 1.24 & 0.37 & 1.13 & 0.28 \\
\hline
\end{tabular}

Notes: 1 The Results for the $\mathrm{h}=6,12$ and 18 are not reported as the results are essentially the same as those for $h=24$.

2 The JK tests were not performed over these sub-periods as simulation studies show the statistic is unreliable for $\mathrm{t}$ less than 36 , see Jobson and Korkie (1981) 